\title{
ASSESSMENT OF SPATIAL GROUNDWATER LEVEL VARIATIONS USING GEOSTATISTICS AND GIS IN HARINGHATA BLOCK, NADIA DISTRICT, WEST BENGAL
}

\author{
Alivia Chowdhury ${ }^{1}$ \\ ${ }^{1}$ Department of Soil and Water Engineering ,Faculty of Agricultural Engineering, Bidhan Chandra Krishi \\ Viswavidyalaya (BCKV), Mohanpur, District-Nadia, 741252, West Bengal, India \\ alivia@rediffmail.com
}

\begin{abstract}
The use of groundwater has increased manifolds in the recent past due to increased water demands owing to the accelerated growth of population and industrialization. A quantitative groundwater assessment study was carried out in Haringhata Block, Nadia district, West Bengal for the sustainable utilization of the vulnerable groundwater resource of the area. In the present study, the spatial variation of groundwater levels was investigated by geostatistical modeling technique in GIS environment. Premonsoon and post-monsoon groundwater depth data of 16 observation locations for 8 year period (2004 to 2011$)$ were considered for the present study. Four geostatistical models namely, linear, circular, Gaussian, and exponential, were selected to understand the spatial variability of the pre-and post-monsoon groundwater depth data in the study area. Finally, the best-fit geostatistical models for pre- and post-monsoon groundwater depth were chosen by comparing the observed values and the values predicted by empirical semi-variogram models. The best-fit geostatistical models were then used to generate spatial maps on pre-and post-monsoon groundwater depth using QGIS 1.2 software. Out of the four semi-variogram models, Spherical model and Gaussian model were found to be the best-fit geostatistical model for pre-monsoon and post-monsoon groundwater depth, respectively for the study area. The results obtained, thus, justify the effectiveness of using geostatistic techniques in investigating the spatial variations of groundwater depths in the study area. This study is helpful in efficient and sustainable utilization of groundwater resources in the block.
\end{abstract}

Keywords: Geostatistics, Groundwater depth, Semi-variogram, Ordinary kriging.

-****

\section{INTRODUCTION}

Groundwater is a major source of freshwater resource in our planet. The use of groundwater has increased manifolds in the recent past due to increased water demands owing to the accelerated growth of population and industrialization. In India, a major percentage of rural population and nearly $30 \%$ of the urban population depend on groundwater resource to meet their fresh water requirements [1]. The use of groundwater has increased strikingly towards agricultural wealth productions than any other sources. The capricious nature of rainfall, use of genetically modified cropping system and implementation of multi-cropping patterns to ensure the food security are some of the major causes towards the elevated dependence on groundwater resources $[2,3]$. Therefore, sustainable management of groundwater resources has become a major issue to the policy makers.

To assess the groundwater scenario in any area, monitoring of groundwater levels in observation wells which are spatially distributed in the area is the main source of information. In any point observations, it is assumed that the measured values can be applicable for a certain area. The more dense the observation points, the more precise the data. In a scattered groundwater observation set-up geostatistical methods can be very effective to determine the water levels for the points where measurements cannot be taken or are not feasible to measure due to economic consideration or any other reasons. Geostatistical methods present a number of tools which are helpful in analyzing spatial variability and spatial interpolation to generate a prediction surface derived from measurements at known locations. The intrinsic uncertainties of groundwater systems can be efficiently analysed using geostatistical tools which include interpolation, integration, and differentiation [4]. Different researchers $[5,6,7,8]$ have investigated the use of geostatistical tools in groundwater study with valuable outcomes.

In addition, nowadays, the use of geographic information system (GIS) has become inevitable for treating and analyzing spatial data in almost every field $[9,10,11]$. The geostatistical modelling can be performed efficiently within GIS environment. Thus, an integrated application of geostatistics and GIS has emerges as a powerful tool for the efficient analysis of spatial and temporal hydrogeologic data. Christakos (2000) [12] investigated the use of geostatistical modeling on water table elevation of about 70 wells in Kansas with successful outcomes. Prakash and Singh (2000) [13] employed kriging technique for understanding the spatial distribution of groundwater in the area and estimated the optimum number of observation 
wells that can be added to the existing network of the study area for better understanding fo groundwater scenario in the area. Kumar and Ahmed (2003) [5] also used kriging method to predict the groundwater level for unmeasured points in the study area for each month of the year using the existing wells data. Ahmadi and Sedghamiz (2007) [6] investigated the use of kriging method to understand the spatial and temporal variations of groundwater level of 39 observation wells. Machiwal et al (2012) [14] used geostatistics and GIS jointly to analyze the spatial and temporal behavior of groundwater depths in a semi-arid hard-rock aquifer. Sahoo and Jha (2014) [15] investigated the spatial variations of groundwater depths using geostatistics in an aquifer of eastern Odisha with successful and beneficial application of the technique.

In this study, geostatistical technique was applied for analyzing the spatial variations of groundwater depth to depict a better picture of the existing aquifer system in the study area. In the present study, four semivariogram models, viz., linear, circular, Gaussian, and exponential model were considered and fitted to the semivariogram model. The best-fit geostatical model was then employed to generate spatial maps of groundwater depths for the study area. This study is useful for understanding the characteristics of aquifer systems in the area which in turn will be helpful for proper utilization and management of this valuable natural resource.

\section{MATERIALS AND METHODS}

\subsection{Study Area}

Haringhata Block, study area of this present study, is located in extreme south of Nadia district of West Bengal. The geographical extent of Haringhata Block lies within a latitude of $22^{0} 54^{\prime} \mathrm{N}$ to $23^{0} 2^{\prime} \mathrm{N}$ and longitude of $88^{0} 30^{\prime} \mathrm{E}$ to $88^{0} 41^{\prime} \mathrm{E}$ which covers an area of about $170.32 \mathrm{Sq}$. Km. The location of the study area is shown in Figure 1. The block comprises of 10 Gram Panchayats (GP).The neighboring block is Chakdah which covers the north and the west boundary of the study area. Whereas the south and east part of the block is bounded by North 24Parganas District. The soil is mainly clay loamy type. The climate is hot and humid during summer followed by a heavy rainfall spell during the monsoon months which continues from June to mid September. Almost $1 / 3$ rd of the annual rainfall occurs during the monsoon months. Average elevation of the block is $10 \mathrm{~m}$ from mean sea level.

\subsection{Groundwater Sampling}

For spatial analysis of groundwater depths, the pre-monsoon and post-monsoon groundwater depth data of 16 observation wells for the 2004-2011 period were collected from State Water Investigation Directorate (SWID), Government of West Bengal, Kolkata; the location of the sites are shown in Fig.1.

\subsection{Modeling Spatial Variation Of Groundwater}

\section{Depth By Geostatistical Technique}

Kriging is a very common and efficient geostatistical interpolation technique that estimates the values of any parameter in unknown areas by judging both the distance and the degree of variation between known data points [16]. In the present study, spatial maps of pre-monsoon and postmonsoon groundwater depths were prepared based on point observations (pre-monsoon and post monsoon groundwater depth data of 16 locations) by kriging technique. During interpolation kriging assumes that things which are close to one another are more similar than those which are farther away (quantified here as spatial autocorrelation) which is common for most of the interpolation methods. The empirical semivariogram investigates and represents this spatial autoorrelation among the data points.

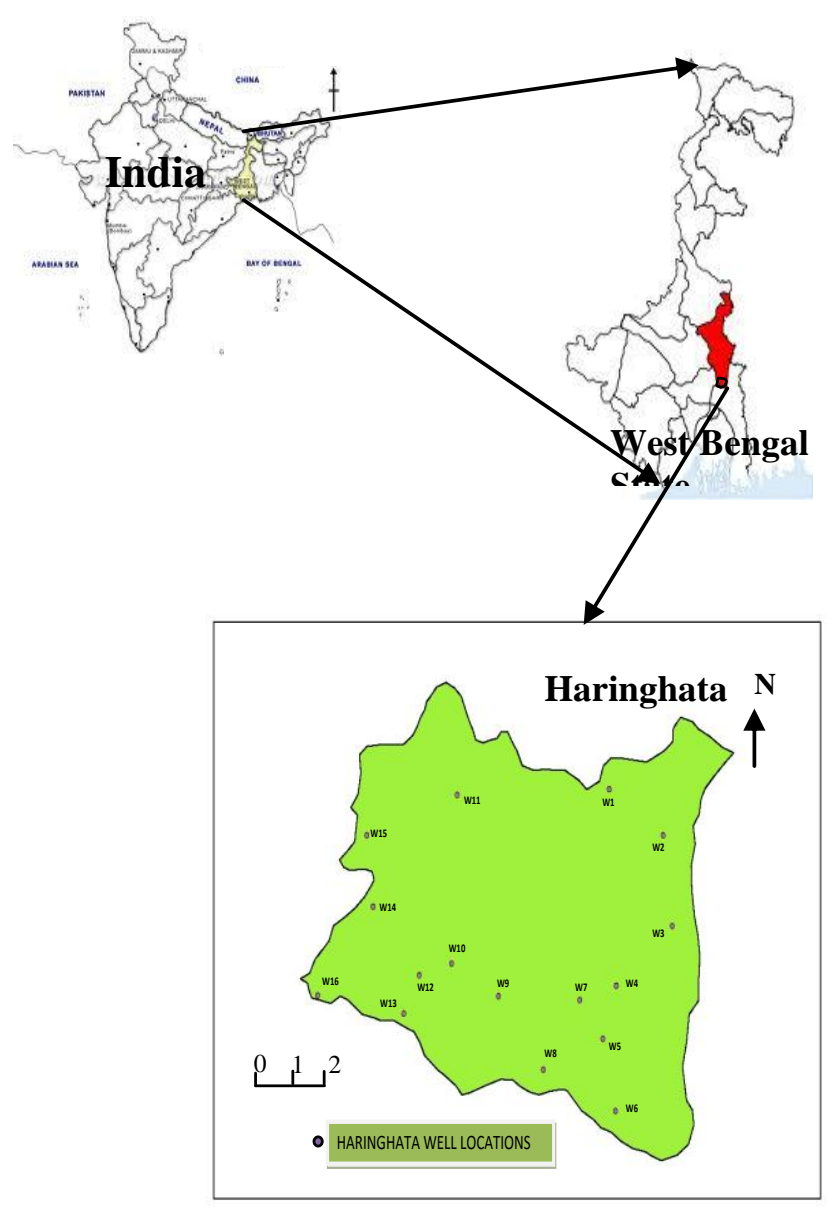

Fig. 1 Location map of the study area

The pre-requisite of kriging methods is a normally distributed data series for its proper functioning. In the present study, the, normality of the spatial groundwater depth data was examined before geostatistical modelling using Quantile-Quantile (QQ) plot in Matlab environment. Then, four geostatistical models namely, linear, circular, Gaussian, and exponential, were fitted to the experimental semivariogram of the pre-monsoon and post-monsoon groundwater depth data. The parameters of the geostatitical 
models, i.e., nugget, sil and range were adjusted. Finally, the best-fit geostatistical models for the groundwater depths of pre- and post-monsoon seasons were selected based highest $\mathrm{R}^{2}$. Semivariogram parameters (Nugget, sill, range) were generated for each theoretical model. The surface maps of pre- and post-monsoon groundwater depths were then produced using the best-fit geostatistical models in QGIS 1.2 software.

\section{RESULTS AND DISCUSSIONS}

\subsection{Modelling Semi-Variogram For Pre- And Post-}

\section{Moonsoon Groundwater Depth}

In the present study, a semivariogram plot is generated in Gamma design software. Four geostatitical models namely exponential, Gaussian, spherical and linear models were selected and fitted to the semivariogram plot to understand the spatial relationship among the data points. Any geostatistical analysis requires its data series to be normally distributed. Therefore, the normality of the groundwater level data was checked by quantile-quantile (QQ) plot (Fig. $2(a, b))$ test in Matlab enviromnment before geostatistical modeling which shows that the groundwater levels (pre- and post-monsoon) follow an approximately normal distribution. Hence, the original data were used for geostatistical modeling. The parameters of the four theoretical geostatistical models (Nugget, Sill and Range) which were fitted to pre and post-monsoon groundwater depths along with goodness-of-fit criteria $\mathrm{R}^{2}$ are presented in Table 1 . It is apparent from Table 1 that the spherical model yields greater prediction accuracy, i.e., and $\mathrm{R}^{2}=0.83$ for premonsoon groundwater depth as compared to the remaining four models. It is also apparent from the table that Gaussian model yields maximum $\mathrm{R}^{2}=0.871$ for post-monsoon groundwater depth, thus selected as the best-fit model. The fitted semi-variogram models for both pre- and postmonsoon groundwater depths are presented in Fig.3 (a, b). The best-fit semivariogram models were used to generate groundwater levels at known points and accuracy of the models were compared with the observed data. A linear regression model and 1:1 line plot were used to check the precision of the models. Results of the linear regression modeling along with 1:1 line are shown in Fig. 4 (a,b). The $\mathrm{r}^{2}$ (coefficient of determination) value for pre-monsoon groundwater depth is 0.751 and for post-monsoon groundwater depth 0.811 which suggest quite good correlation between observed groundwater level values and groundwater levels values predicted by the selected semivariogram models.
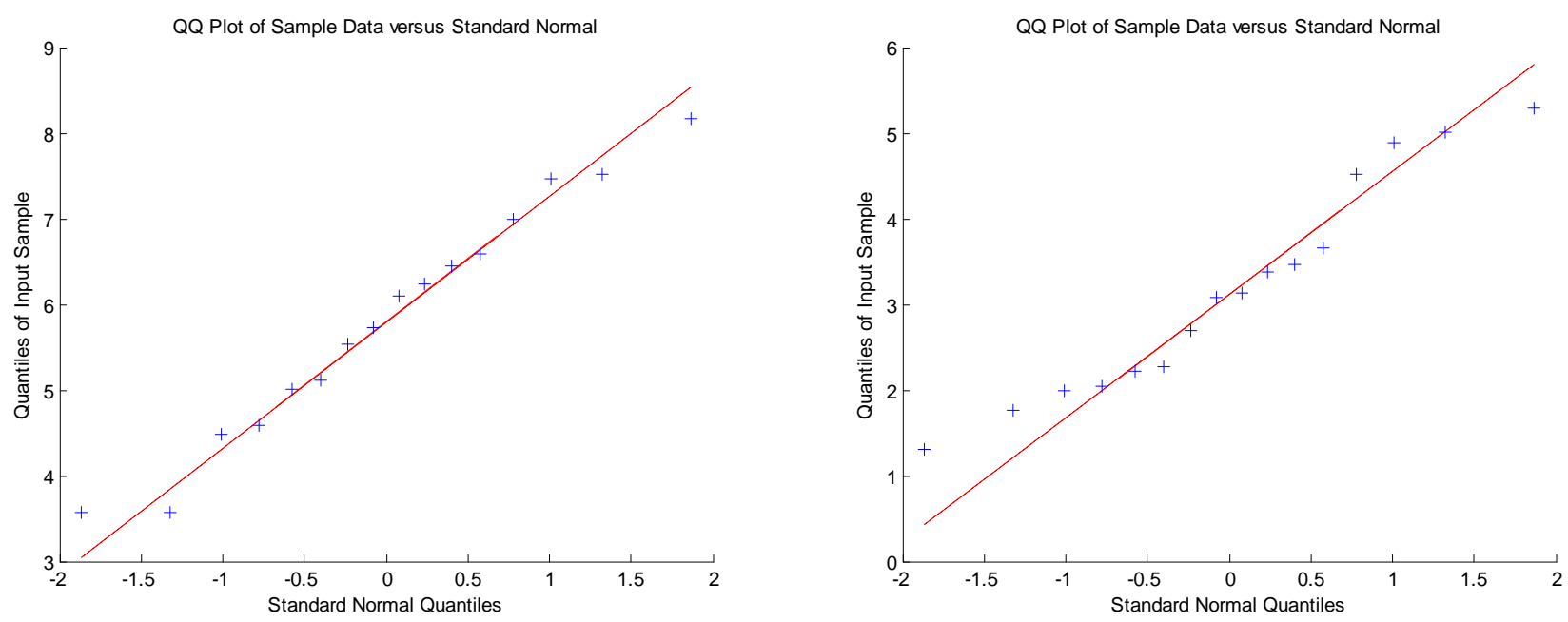

Fig. 2 Quantile-quantile plot of pre-monsoon (a) and post-monsoon (b) groundwater level data

Table 1. Parameters of four geostatistical models for spatial analysis of pre-monsoon and post-monsoon groundwater level

\begin{tabular}{|l|l|l|l|l|l|l|l|l|}
\hline \multirow{2}{*}{$\begin{array}{l}\text { Geostatistical } \\
\text { Models }\end{array}$} & \multicolumn{4}{|l|}{ Parameters } & \multicolumn{4}{l|}{ Post-monsoon groundwater depth } \\
\cline { 2 - 9 } & \begin{tabular}{l} 
Pre-monsoon groundwater depth \\
\cline { 2 - 9 } \\
$\left(\mathrm{m}^{2}\right)$
\end{tabular} & $\begin{array}{l}\text { Sugget } \\
\left(\mathrm{m}^{2}\right)\end{array}$ & $\begin{array}{l}\text { Range } \\
(\mathrm{km})\end{array}$ & $\mathrm{R}^{2}$ & $\begin{array}{l}\text { Nugget } \\
\left(\mathrm{m}^{2}\right)\end{array}$ & $\begin{array}{l}\text { Sill } \\
\left(\mathrm{m}^{2}\right)\end{array}$ & $\begin{array}{l}\text { Range } \\
(\mathrm{km})\end{array}$ & $\begin{array}{l}\mathrm{R}^{2} \\
\text { Spherical }\end{array}$ \\
\hline Exponential & 0.04 & 4.4 & 10.73 & $\mathbf{0 . 8 3}$ & 0.06 & 1.63 & 32.63 & 0.84 \\
\hline Gaussian & 0.05 & 5.1 & 34.61 & 0.76 & 0.08 & 1.85 & 25.67 & 0.81 \\
\hline Linear & 0.06 & 4.8 & 20.28 & 0.78 & 0.058 & 1.914 & 34.59 & $\mathbf{0 . 8 7 1}$ \\
\hline
\end{tabular}


pre-monsoon GW depth: Isotropic Variogram

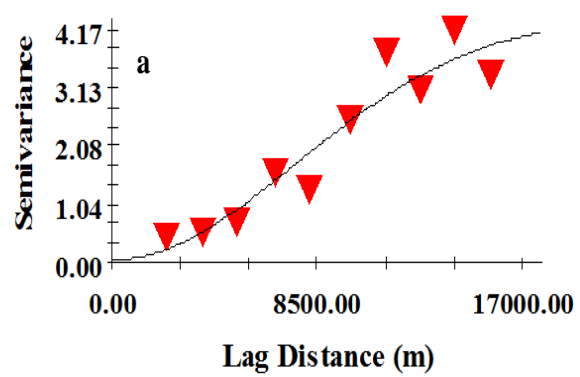

post monsoon GW depth: Isotropic Variogram

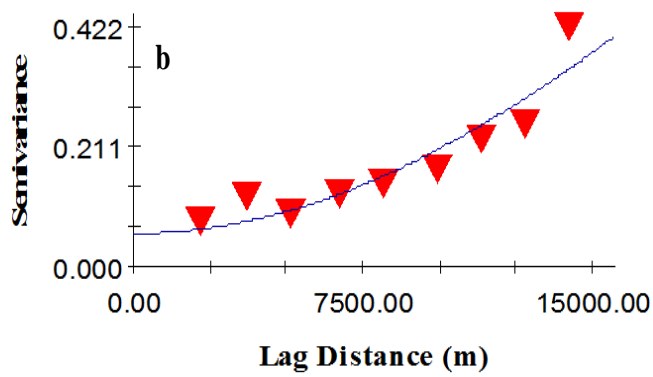

Fig. 3 Fitted semivariogram (a) spherical model for pre-monsoon groundwater depths and (b) Gaussian model for post-monsoon groundwater depths.
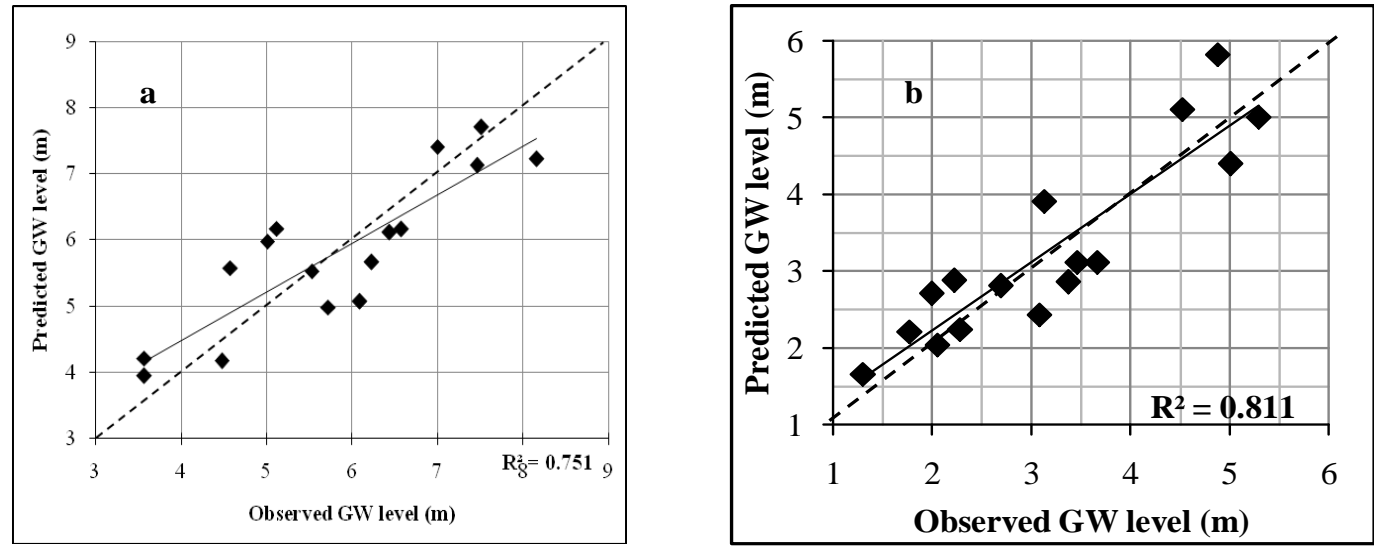

Fig. 4 The best-fitted regression model (solid line) between (a) the observed and predicted pre-monsoon groundwater levels and 1:1 line (dashed line) and (b) the observed and predicted post-monsoon groundwater levels and 1:1 line (dashed line)

\subsection{Generation of Surface Maps of Pre-Monsoon} and Post-Monsoon Groundwater Level.

After model validation, the surface maps were generated for both pre-monsoon and post-monsoon groundwater depth (Figure 5 a,b). The surface map of 8-year (2004-2011) mean pre-monsoon groundwater depth of the study area prepared by spherical geostatistical model reveals that the mean premonsoon groundwater depth in the area varies from 3.5 to 8 $\mathrm{m}$ below ground surface ( $\mathrm{m} \mathrm{bgs}$ ) with a major portion of the area having 5 to $7 \mathrm{~m}$ bgs depth (Fig. 5(a)).

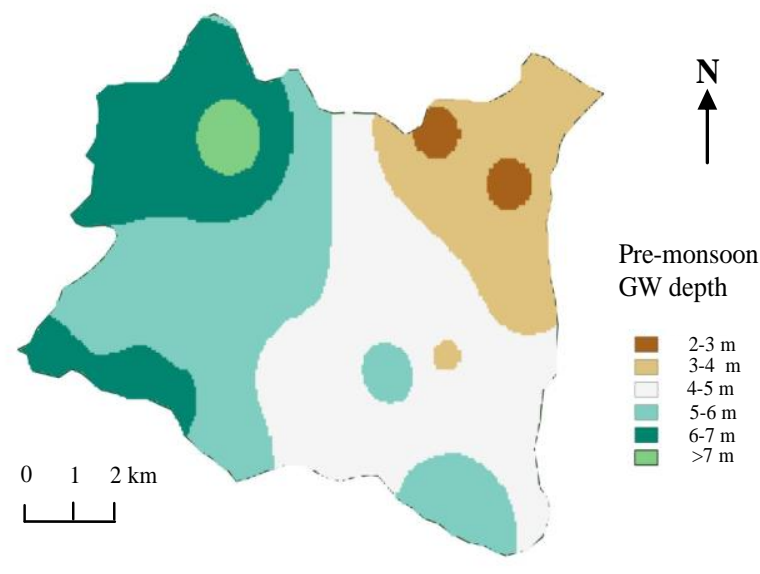

a

Fig. 5 (a). Spatial distribution map for pre-monsoon groundwater depths of Haringhata Block.

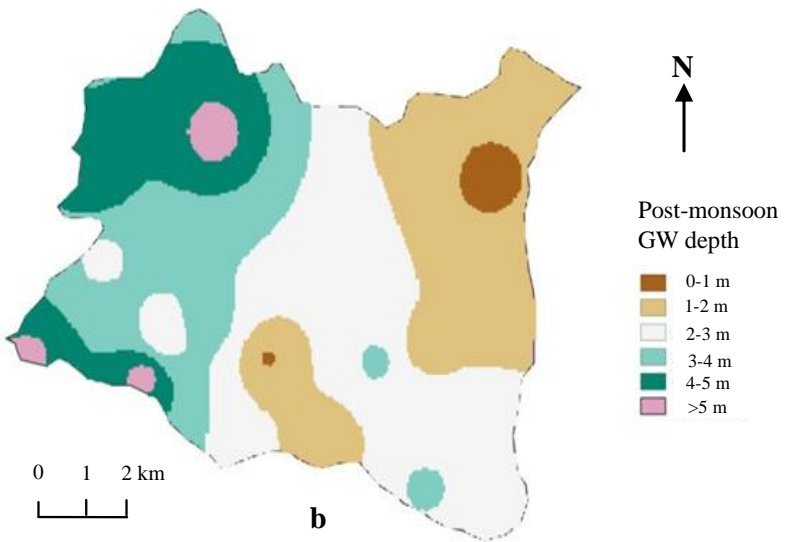

Fig. 5 (b). Spatial distribution map for post-monsoon groundwater depths of Haringhata Block.

On the other hand, the surface map of 8-year (2004-2011) mean postmonsoon groundwater depth (Gaussian geostatistical model) (Fig. 5 (b)) reveals that the groundwater depth varies from 0.9 to $5.3 \mathrm{~m}$. Spatial distribution of post-monsoon groundwater also reveals that eastern part of the block has high post-monsoon groundwater depth below surface compare to the western part of the block.

\section{CONCLUSIONS}

Sustainable and efficient maintenance of vulnerable groundwater resource is the need of the hour which requires 
apt management strategies to adopt. The present study aims at spatial analysis of groundwater depth of Haringhata block, Nadia District using a combined approach of geostatistics and GIS. In the present study, four semivriogram models were tested for pre- and post-monsoon groundwater depth data. The study revealed that Spherical model and Gaussian model were found to be the best-fit geostatistical models for pre-monsoon groundwater depth and post-monsoon groundwater depth, respectively for the study area, which were used for developing contour maps of pre- and post-monsoon groundwater depth. The surface map of 8-year (2004-2011) mean pre-monsoon groundwater depth generated by kriging technique (spherical geostatistical model) reveals that the mean pre-monsoon groundwater depth in the area generally varies from 3.5 to 8 $\mathrm{m}$ below ground surface ( $\mathrm{m}$ below ground surface) with a major portion of the area having 5 to $7 \mathrm{~m}$ depth below ground surface. On the other hand, the surface map of 8 year (2004-2011) mean postmonsoon groundwater depth (Gaussian geostatistical model) reveals that the groundwater depth varies from 0.9 to $5.3 \mathrm{~m}$. Spatial distribution of postmonsoon groundwater also reveals that eastern part of the block has high post-monsoon groundwater depth below surface compare to the western part of the block. The results obtained suggest the usefulness of applying geostatistic techniques in investigating the spatial variations of groundwater depths in the study area. Overall, it could be concluded that an integrated application of geostatistics and geographical information system could be an effective approach for sustainable management of groundwater resources.

\section{ACKNOWLEDGEMENTS}

The author gratefully acknowledges the State Water Investigation Directorate (SWID), Government of West Bengal, Kolkata for providing necessary groundwater-level data for the present study.

\section{REFERENCES:}

[1]. Reddy, K.R., \& Adams, J.A. (1996), "In situ air sparging: a new approach for ground water remediation", Geotech News, 14(4), 27-32.

[2]. Tiwari V,M., Wahr, J,. Swenson, S. (2009), "Dwindling groundwater resources in northern India, from satellite gravity observations", Geophysical Research Letters, 36, L18401, doi:10.1029/2009GL039401.

[3]. Naik, P.K and Awasthi, A.K. (2003), "Groundwater resources assessment of the Koyna river basin, India", Hydrogeology, 11, 582-594.

[4]. ASCE Task Committee. (1990). Review of geostatistics in geohydrology. I: Basic concepts. Journal of Hydraulic Engineering, ASCE, 116(5), 612632.

[5]. Kumar, D., \& Ahmed, Sh. (2003). Seasonal behaviour of spatial variability of groundwater level in a granitic aquifer in monsoon climate Current Science, 84, 188196.
[6]. Ahmadi, S. H., \& Sedghamiz, A. (2007). Geostatistical analysis of spatial and temporal variations of groundwater level. Environmental Monitoring and Assessment, 129, 277-294.

[7]. Uyan, M. and Cay, T. (2010). Geostatistical methods for mapping groundwater nitrate concentrations. 3rd International Conference on Cartography and GIS 1520 June, 2010, Nessebar, Bulgaria.

[8]. Adhikary, P.P., Dash, Ch.J., Chandrasekharan, H., Rajput, B. S. and Dubey, S. K. (2012). Evaluation of groundwater quality for irrigation and drinking using GIS and geostatistics in a peri-urban area of Delhi, India. Arab Journal of Geoscience, Vol 5:1425-1434.

[9]. Stafford,D.B.(Ed.).(1991).Civil engineering applications of remote sensing and geographic information systems. New York:ASCE.

[10].Goodchild, M. F., Parks, B. O., \& Steyaert, L. T. (Eds.). (1993). Environmental modeling with GIS. New York: Oxford University Press.

[11].Chen, Y., Takara, K., Cluckie, I. D., \& Smedt, F. H. D. (Eds.). (2004). GIS and remote sensing in hydrology, water resources and environment. IAHS Publication No. 289. Wallingford: IAHS Press.

[12].Christakos, G. (2000). Modern spatiotemporal geostatistics. New York, USA: Oxford University Press.Geology, 39, 628-632.

[13].Prakash, M. R., \& Singh, V. S. (2000). Network design for groundwater monitoring - A case study. Environmental Geology, 39, 628-632.

[14].Machiwal, D., Mishra, A., Jha, M.K., Sharma, A. and Sisodia, S.S. (2012). Modeling hort-term spatial and temporal variability of groundwater level using geostatistics and GIS. Natural Resource Research, Vol 21, No1: 177-136.

[15].Sahoo, S. and Jha, M.K. (2014). Analysis of spatial variation of groundwater depths using geostatistical modeling. International Journal of Applied Engineering Research, Volume 9, Number 3 (2014) pp. 317-322.

[16].Goovaerts, P. (1997). Geostatistics for natural resources evaluation. New York: Oxford University Press. 